\title{
Perfil do geoturista do Parque Estadual da Serra do Rola-Moça (MG) ${ }^{1}$
}

\author{
Geotourist Profile of "Serra do Rola-Moça" State Park \\ (MG, Brazil)
}

\author{
Ricardo Eustáquio Fonseca Filho, Gabriela Sousa Ribeiro
}

\begin{abstract}
RESUMO
O Parque Estadual da Serra do Rola-Moça (PESRM) é uma unidade de conservação de Proteção Integral em Minas Gerais, com características geológicas e geomorfológicas que o caracterizam como um geossítio do Geoparque do Quadrilátero Ferrífero, com alto potencial para o geoturismo. A pesquisa teve por objetivo conhecer o perfil do visitante do PESRM, na tentativa de identificar se há entre os visitantes potenciais geoturistas. A metodologia incluiu revisão bibliográfica e digital, e trabalho de campo, por meio da aplicação de questionários estruturados qualitativo-quantitativo a 50 visitantes. Os resultados demonstram que o visitante do Parque, em sua maioria, não sabe o que é geoturismo $(57 \%)$ e que está em um geoparque (64\%), é mineiro (86\%), homem $(68 \%)$, casado $(58 \%)$, jovem (68\% entre 26 e 45 anos de idade), católico (42\%), viaja com a família (36\%), excursionista $(97,96 \%)$, utiliza o veículo próprio (74\%), motivado por contemplação da natureza $(36 \%)$, economicamente da classe B (44\%) e boa escolaridade (50\% nível superior). Desta forma, o perfil do geoturista é de "nível I" (curioso) demonstrando necessidade de melhor interpretação do segmento por meio de um programa educacional de uso público para as geociências.
\end{abstract}

PALAVRAS-CHAVE: Geoturista; Demanda Turística; Parque Estadual Serra do Rola-Moça; Unidades de Conservação; Ecoturismo.

\section{ABSTRACT}

The Rola-Moça Range State Park is an Integral Protection nature protected area in Minas Gerais (MG), Brazil, with geological and geomorphological features that characterize it as a geosite in the Ferriferous Quadrangle Geopark, with high potential for geotourism. The research aimed to know the Park visitor profile in an attempt to identify whether there is among potential visitors geotourists. The methodology included bibliographic and digital review, and field work, through the application of qualitative and quantitative structured questionnaires to 50 visitors. The results show that the visitor's Park, mostly, do not know what is geotourism (57\%) and is in a geopark (64\%); is from MG (86\%); male (68\%); married $(58 \%)$; young (68\% between 26 and 45 years old); Catholic (42\%); traveling with family $(36 \%)$; excursionist $(97.96 \%)$; using the vehicle itself $(74 \%)$; driven by the contemplation of nature (36\%); economically middle class (44\%); and good education (50\% higher level). Thus, the geotourist profile is "Level I" (curious) demonstrating need for better interpretation of the segment through an educational program for public use for the geosciences.

KEYWORDS: Geotourist; Tourist Demand; Rola-Moça Range State Park; Natural Protected Areas; Ecotourism. 


\section{Introdução}

O andar civilizatório levou áreas prístinas à ocupação artificial. Redutos naturais voltados à preservação de seus recursos como as unidades de conservação (UC) foram um dos poucos espaços que restaram. Além da preservação servem também para o lazer, como os parques. O Brasil, rico em áreas naturais, tem em Minas Gerais um destaque com 80 unidades de conservação estaduais (IEF, 2014). Dentre elas o Parque Estadual da Serra do Rola-Moça (PESRM), unidade de conservação de Proteção Integral, sendo este o terceiro maior parque em área urbana do Brasil, situado nos municípios de Belo Horizonte, Brumadinho, Ibirité e Nova Lima (MG).

A razão principal para o desenvolvimento desta pesquisa é traçar o perfil do visitante do PESRM com o intuito de identificar potenciais geoturistas existentes neste parque. Logo, o objetivo geral desta monografia é identificar o perfil do potencial geoturista do PESRM sendo os objetivos específicos investigar se 0 Instituto Estadual de Florestas (IEF) tem conhecimento do segmento turístico geoturismo bem como do potencial de desenvolvimento deste segmento neste parque.

Uma das hipóteses existentes para esta pesquisa é a de que existe o perfil de visitantes que se enquadram dentro do segmento do geoturismo, praticando-o mesmo que inconscientemente. Outra hipótese é que o IEF conhece o segmento de geoturismo e potencial de desenvolvimento para o parque.

Os materiais e métodos utilizados se dividiram em duas etapas, sendo: I) Escritório: submissão de projeto de iniciação científica e licença de pesquisa no IEF; revisão bibliográfica e digital sobre Unidades de Conservação (UC), PESRM, geoturismo, ecoturismo e demanda turística; elaboração de instrumento de coleta de dados questionário quali-quantitativo composto por 46 questões, sendo 36 fechadas e 10 abertas/semi-abertas, dividido em três partes (turismo, geoturismo, sócioeconomia); e tabulação, elaboração de figuras (no programa Windows Exce ${ }^{\circledR}$ versão Microsoft Office ${ }^{\circledR}$ - 2003) e análise e discussão dos resultados; e II) Campo: aplicação de questionários por três entrevistadores a amostra de 50 visitantes do PESRM em cinco atrativos da UC no período de 01/05/2015 à 03/05/2015, incluindo dia útil e fim de semana em baixa estação turística.

\section{Turismo em áreas naturais e seus segmentos}

O Turismo é um fenômeno social, econômico e cultural que vem se destacando no cenário mundial, principalmente como atividade econômica que possui elevado desenvolvimento e que gera uma lucratividade considerável. Segundo a Organização Mundial do Turismo - OMT (2001), o turismo é definido como "as atividades que as pessoas realizam durante viagens e estadas em lugares diferentes do seu entorno habitual, por um período inferior a um ano, com finalidade de lazer, negócios ou outras".

No entanto, são muitos os aspectos envolvidos para a realização desta atividade tais como: hospitalidade, transportes, políticas públicas, agenciamento, hotelaria, alimentos e bebidas, bem como os atrativos turísticos.

Por se tratar de uma atividade complexa que abrange diferentes áreas e que se manifesta através de diversas práticas, o turismo é dividido em segmentos 
distintos com o intuito de facilitar o planejamento e gestão do mesmo. A identidade da oferta (definida através das tradições, manifestações culturais e religiosas bem como características físicas, geográficas, históricas, sociais e arquitetônicas) como também as especificidades e variáveis da demanda (preferências, motivações), são elementos utilizados para a segmentação do turismo. No Brasil, foram estabelecidos pelo Ministério do Turismo - MTUR (2006) alguns segmentos prioritários para o desenvolvimento da atividade turística, dentre eles o Ecoturismo.

Na pesquisa foi abordado assim o turismo em áreas naturais:

um segmento do turismo que utiliza o patrimônio natural e cultural, de forma sustentável, com intercâmbio sob diferentes formas entre o homem e a natureza, para promover a conservação dos recursos locais (físicos e humanos), otimizando os custos e ganhos ambientais, culturais, econômicos e sociais, orientado por planejamentos participativos (DIRETRIZES PARA O TURISMO EM ÁREAS NATURAIS NO PARANÁ, 2000, p. 4).

As práticas deste segmento são realizadas principalmente em áreas protegidas, também conhecidas como UC

espaço territorial e seus recursos ambientais, incluindo as águas jurisdicionais, com características naturais relevantes, legalmente instituído pelo Poder Público, com objetivos de conservação e limites definidos, sob regime especial de administração, ao qual se aplicam garantias adequadas de proteção (BRASIL, 2000).

O Sistema Nacional de Unidades de Conservação da Natureza (SNUC) ${ }^{2}$ bem como o MMA consideram o turismo como uma atividade passível de ser desenvolvida dentro das UC. Entretanto, o planejamento e gestão da visitação nas áreas protegidas devem estar de acordo com os objetivos dos planos de manejo das mesmas (MMA, 2006, p.13).

Segundo Muniz e Pires (2010):

a visitação através da recreação, educação ambiental e turismo, em princípio, estão contemplados nos objetivos básicos dos dois grupos, salvaguardando-se apenas duas categorias de unidades de conservação (Estação Ecológica, Reserva Biológica) onde a visitação pública é vedada ou restrita a condições muito especiais. Das unidades de conservação, a categoria "Parque" integrante do grupo de proteção integral, é a mais vocacionada para a visitação, uma vez que contempla em seus objetivos básicos.

Dentre as modalidades englobadas no turismo de natureza, o ecoturismo é o segmento que atualmente possui maior visibilidade. Para Lindberg e Hawkins (1995, p.18) o "ecoturismo é provocar e satisfazer o desejo que temos de estar em contato com a natureza, é explorar o potencial turístico visando à conservação e ao 
desenvolvimento, é evitar o impacto negativo sobre a ecologia, a cultura e a estética".

Apesar de ser um segmento turístico consolidado e em constante desenvolvimento, o ecoturismo promove uma usual valorização da biodiversidade, deixando de lado outra parte do ambiente, tão importante quanto este, a geodiversidade. É na intenção de buscar a valorização para além da biodiversidade ${ }^{3}$, abrangendo e destacando assim a geodiversidade ${ }^{4}$, que um novo segmento turístico vem sendo desenvolvido e trabalhado, denominado "geoturismo".

\section{Geoturismo como possibilidade para o turismo em áreas naturais}

O geoturismo é uma nova tendência em termo de turismo em áreas naturais, que tem como prioridade a valorização da geodiversidade. Assim como o ecoturismo ambos estão inseridos no contexto do turismo em áreas naturais e prezam pela preservação do Patrimônio Natural, sendo estes segmentos complementares embora diferentes uma vez que possuem características específicas.

Para Moreira (2010, p. 5) "o Geoturismo não pode ser encarado como uma forma de Ecoturismo, e sim como um novo segmento, que conta inclusive com a aprovação e incentivos por parte da UNESCO, sendo específico em suas potencialidades e objetivos".

A primeira vez em que o termo geoturismo foi utilizado cientificamente para designar um segmento turístico foi em 1995, pelo inglês Thomas Hose, onde ele conceituou geoturismo como "provisão de serviços e facilidades interpretativas no sentido de possibilitar aos turistas a compreensão e aquisição de conhecimentos de um sítio geológico ${ }^{5}$ e geomorfológico ao invés da simples apreciação estética" (HOSE, 1995 apud MOREIRA, 2010, p.6).

Em 2000 a definição foi reconsiderada, caracterizando o geoturismo a

disponibilização de serviços e meios interpretativos que promovem o valor e os benefícios sociais de lugares com atrativos geológicos e geomorfológicos, assegurando sua conservação, para o uso de estudantes, turistas e outras pessoas com interesses recreativos e de ócio (HOSE apud MOREIRA, 2010, p.6).

Embora seja um conceito abordado em estudos recentes, o geoturismo possui elementos importantes relacionados que embasam seu fundamento e sua consolidação. Dentre estes elementos, podem ser citados os conceitos de "geodiversidade" e de "geoconservação", que juntamente ao geoturismo formam um trinômio importante na área das geociências e estes visam à preservação do "patrimônio geológico"6.

A proteção do patrimônio pode-se dar por meio da conservação ou da preservação. A preservação considera que, para a efetiva proteção, os patrimônios devem ser mantidos intactos, sem quaisquer modificações, intocados. [...] A conservação compreende que os patrimônios passem por mudanças, já que representam o testemunho de uma determinada época e se adaptam com o passar do tempo (RUCHKYS, 2007, p.10). 
Neste sentido a ideia de preservação não se aplica como forma de proteção da geodiversidade assim como do patrimônio geológico uma vez que por se tratar de patrimônio natural os mesmos estão sujeitos a dinâmica natural que leva a constantes modificações (RUCHKYS, 2007). Assim sendo a conservação é a melhor forma de se proteger os atributos geológicos. Na tentativa de aperfeiçoar o processo de conservação, foi desenvolvido um termo específico, caracterizado prioritariamente pela conservação da geodiversidade, a geoconservação ${ }^{7}$.

Nessa perspectiva, para além das unidades de conservação, qual o espaço protegido para auxiliar na relação e valorização do homem com os componentes abióticos da Terra? A resposta foi a criação do conceito de "geoparque"8.

Os "Geoparks" são reconhecidos pela Global Geoparks Network - GGN, desde 2004 operando de acordo com os regulamentos da União das Nações Unidas para a Educação, Ciência e Cultura - UNESCO (SCHOBBENHAUS, SILVA, 2012; CPRM, 2015). De um total de 120 geoparques reconhecidos pela GGN/UNESCO em 33 países há no Brasil o Geopark do Araripe, criado em 2006 e abrangendo o extremo sul do Estado do Ceará, noroeste do Pernambuco e leste do Piauí (GEOPARK ARARIPE, 2016).

De acordo com o Serviço Geológico do Brasil (2015), até 2014 já existiam 37 propostas de geoparques espalhadas por 19 Estados brasileiros. E é no Geoparque do Quadrilátero Ferrífero que está inserido, dentre outras UC, o Parque Estadual Serra do Rola-Moça, recorte espacial amostrado nesta pesquisa.

A área do Geoparque do Quadrilátero Ferrífero (Figura 1) ocupa aproximadamente $7.000 \mathrm{~km}^{2}$ estando situado na porção centro-sudeste do Estado de Minas Gerais, sendo ele internacionalmente reconhecido como um importante terreno Pré-Cambriano com significativos recursos minerais, em especial ouro e ferro (AZEVEDO et al., 2012). 


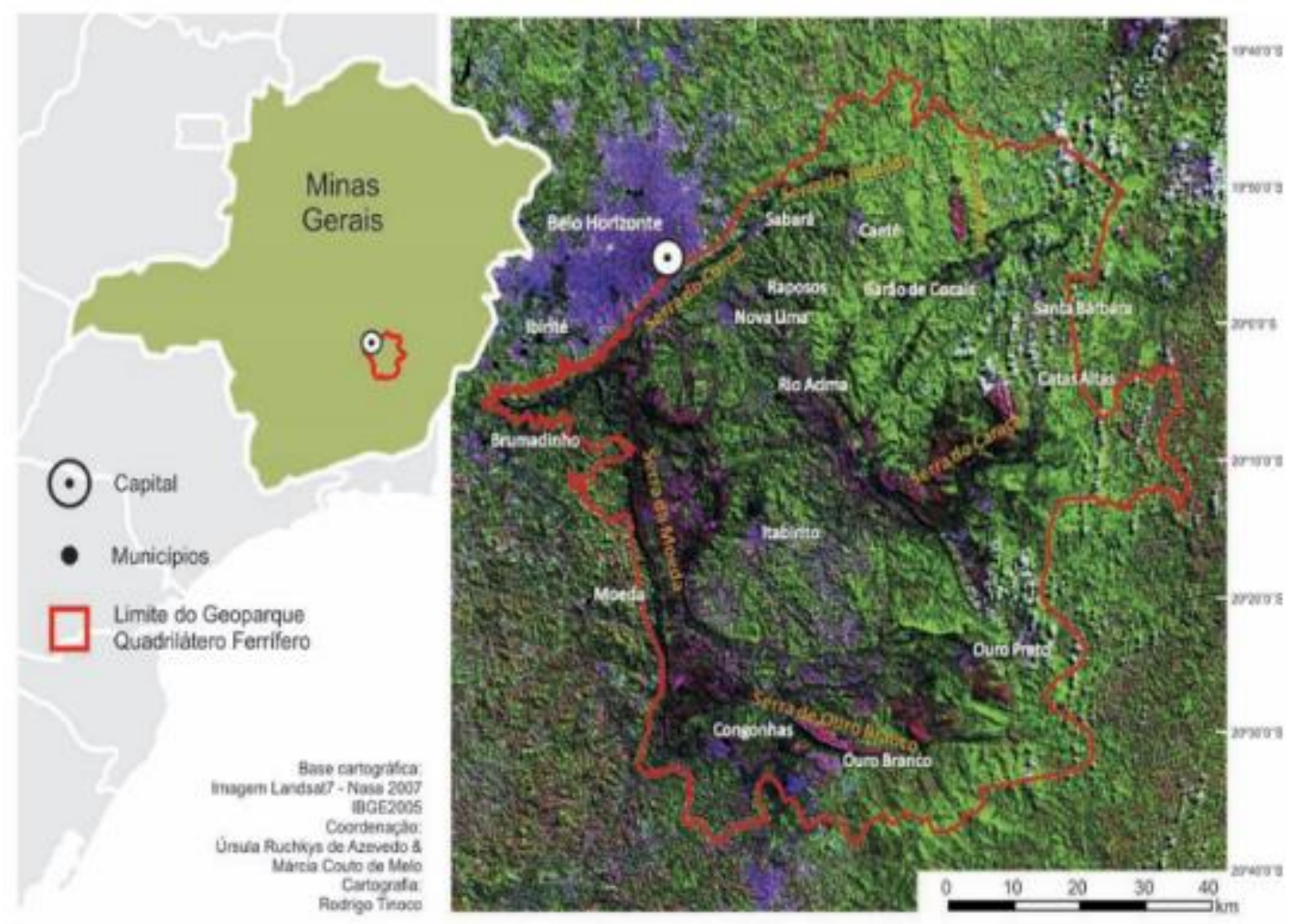

Figura 1: Localização do Geoparque do Quadrilátero Ferrífero. Fonte: Azevedo et al. (2012).

Figure 1: Location of Ferriferous Quadrangle Geopark. Source: Azevedo et al. (2012).

A criação e efetivação deste bem como dos demais geoparques implicam o desenvolvimento da atividade turística no local, uma vez que ela será responsável pelo desenvolvimento social e econômico do local. Contudo vê-se que os Geoparques foram e vem sendo criados em uma perspectiva de difundir e trabalhar os conceitos geocientíficos até então abordados.

Desde meados do Séc. XIX momento em que foram criadas as primeiras áreas protegidas do mundo, sendo a primeira o Parque Nacional Yellowstone, em 1872, nos Estados Unidos da América, observa-se que o objetivo principal de criação das mesmas foi o de proteção do patrimônio natural e cultural. Segundo a UNESCO (2015), "Patrimônio Natural Mundial significa as formações físicas, biológicas e geológicas excepcionais, habitats de espécies animais e vegetais ameaçadas e áreas que tenham valor científico, de conservação ou estético excepcional ou universal". Já o "Patrimônio Cultural Mundial é composto por monumentos, grupos de edifícios ou sítios que tenham um excepcional e universal valor histórico, estético, arqueológico, científico, etnológico, ou antropológico" (idem).

Apesar do conceito de patrimônio natural incluir o ambiente como um todo, formado por seus aspectos físicos, biológicos e geológicos, nota-se que, na prática, o enfoque da preservação nas unidades de conservação é voltado prioritariamente para a biodiversidade, sem ênfase na geodiversidade. Sendo assim, aspectos geológicos das áreas protegidas de forma geral foram e vem sendo pouco explorados, tanto em questões legais, quanto em sua utilização científica e, até mesmo, turística.

Na maioria dos países, no contexto das legislações existentes sobre a conservação de áreas protegidas, as referências diretas sobre a proteção do patrimônio geológico aparecem de forma implícita, com 
denominações como recursos naturais, paisagem e ecossistemas. A ocorrência de valores geológicos enquadrados em áreas protegidas, frequentemente, é uma mera coincidência. No Brasil, os fenômenos geológicos têm sido protegidos de forma casual, entre os valores biológicos, estéticos e culturais, em vez de serem por seus próprios valores científicos (RUCHKYS, 2007, p.11).

Entretanto, esse quadro tende se reverter na medida em que especialistas das geociências e áreas afins, evidenciando a transdisciplinaridade das ciências naturais e da educação ambiental, difundem os valores bem como a relevância dos atributos geológicos tanto como base para a biodiversidade como pelo valor histórico e científico que ele contém daí a importância em criar meios de preservá-los.

Assim sendo o geoturismo entra como forma de consolidação e alcance dos objetivos da comunidade das Ciências da Terra e áreas afins. Isso se explica pelo falo de a geoconservação e o geoturismo estar articulados um ao outro uma vez que um tende a promover o outro.

Acredita-se que a atividade turística, se bem planejada e direcionada, possa contribuir para a proteção do patrimônio, uma vez que esta atividade depende de atrativos bem conservados. A contribuição do turismo para a proteção do patrimônio pode acontecer por meio da sensibilização do turista em relação à importância dos atrativos que visita (RUCHKYS, 2007, p.22).

A autora (2007, p.23) considera ainda que "a interpretação é um componente essencial do geoturismo, pois é ela que encoraja o turista a contribuir para a geoconservação".

Neste sentido, tem-se a interpretação definida como "uma atividade educativa que objetiva revelar significados e as relações existentes no ambiente, por meio de objetos e experiências, com a utilização de meios ilustrativos, em vez de comunicar informações e fatos" (TILDEN, 1957 apud RUCHKYS, 2007).

Além deste geoparque o geoparque do Quadrilátero Ferrífero, MG no qual está inserido, entre outras unidades de conservação, o Parque Estadual Serra do Rola-Moça, também desenvolve atividades (geo)turísticas, já que envolvem, mesmo que implicitamente, sua geodiversidade.

\section{Parque Estadual Serra do Rola-Moça: análise de sua atividade (geo)turística local}

Atualmente existem cerca de 1.940 unidades de conservação brasileiras totalizando uma área total de $1.551 .196 \mathrm{~km}^{2}$ (Figura 2), sendo elas geridas em todas as esferas governamentais: federal, estadual e/ou municipal; e divididas em duas categorias: de Proteção Integral e de Uso Sustentável, sendo estas de uso indireto dos recursos naturais e aquelas indireto (CNUC/MMA, 2015).

O Parque Estadual Serra do Rola-Moça, de proteção integral, gerido pelo Instituto Estadual de Florestas (IEF) se localiza na parte central do Estado de Minas Gerais, na região do Quadrilátero Ferrífero ${ }^{9}$, porção sul do complexo da Serra do Espinhaço. Possui uma área total de 3.942 hectares, sendo o terceiro maior parque em área urbana do país (BIODIVERSITAS, 2007). 


\section{De acordo com o Plano de Manejo do PESRM}

o Parque Estadual Serra do Rola-Moça foi criado em 27 de setembro de 1994 pelo Decreto Estadual $n^{\circ} 36.071$, para proteger os seis importantes mananciais de água [grifo nosso] que abastecem parte da população de Belo Horizonte, lbirité e Brumadinho. De forma a assegurar $\mathrm{o}$ fornecimento de água em qualidade, quantidade e constância, esses mananciais foram declarados como Áreas de Proteção Especial (APE's), pelo governo estadual (BIODIVERSITAS, 2007, p.11).

Para além da proteção dos recursos hídricos a origem do nome do Parque está associada a um causo contado em um poema do escritor modernista Mário de Andrade, que:

Relata a história de um casal que, logo após a cerimônia de casamento, cruzaram a serra de volta para casa, quando o cavalo da moça, escorregou no cascalho e caiu no fundo do grotão. O marido, desesperado, esporou seu cavalo ribanceira abaixo e, "a Serra do Rola-Moça, Rola-Moça se chamou" (idem, p.12).

Tabela consolidada das Unidades de Conservaçäo

Fonte: CNUC/MMA - WWW.mma.gov.br/cadastro_uc Atualizada em: 17/02/2015

\begin{tabular}{|c|c|c|c|c|c|c|c|c|}
\hline \multirow{3}{*}{$\begin{array}{l}\text { Tipo / Categoria } \\
\text { Proteçăo Integral }\end{array}$} & \multicolumn{6}{|c|}{ Esfera } & \multirow{2}{*}{\multicolumn{2}{|c|}{ TOTAL }} \\
\hline & \multicolumn{2}{|c|}{ Federal } & \multicolumn{2}{|c|}{ Estadual } & \multicolumn{2}{|c|}{ Municipal } & & \\
\hline & $\mathrm{N}^{0}$ & Área $\left(\mathrm{Km}^{2}\right)$ & $\mathrm{N}^{0}$ & Área $\left(\mathrm{Km}^{2}\right)$ & $\mathrm{N}^{0}$ & Área $\left(\mathrm{Km}^{2}\right)$ & $\mathrm{N}^{0}$ & Área $\left(\mathrm{Km}^{2}\right)$ \\
\hline Estaçăo Ecológica & 32 & 74.691 & 58 & 47.513 & 1 & 9 & 91 & 122.213 \\
\hline Monumento Natural & 3 & 443 & 28 & 892 & 11 & 73 & 42 & 1.407 \\
\hline Parque Nacional / Estadual / Municipal & 71 & 252.978 & 195 & 94.889 & 95 & 221 & 361 & 348.088 \\
\hline Refúgio de Vida Silvestre & 7 & 2.017 & 24 & 1.729 & 1 & 22 & 32 & 3.768 \\
\hline Reserva Biológica & 30 & 39.034 & 24 & 13.449 & 6 & 48 & 60 & 52.531 \\
\hline Total Proteçăo Integral & 143 & 369.164 & 329 & 158.472 & 114 & 372 & 586 & 528.007 \\
\hline
\end{tabular}

\begin{tabular}{|c|c|c|c|c|c|c|c|c|}
\hline Uso Sustentável & $\mathrm{N}^{0}$ & Área $\left(\mathrm{Km}^{2}\right)$ & $\mathrm{N}^{0}$ & Área $\left(\mathrm{Km}^{2}\right)$ & $\mathrm{N}^{0}$ & Área $\left(\mathrm{Km}^{2}\right)$ & $\mathrm{N}^{0}$ & Área $\left(\mathrm{Km}^{2}\right)$ \\
\hline Floresta Nacional / Estadual / Municipal & 65 & 163.913 & 39 & 136.053 & 0 & 0 & 104 & 299.966 \\
\hline \begin{tabular}{|l|} 
Reserva Extrativista \\
\end{tabular} & 62 & 124.362 & 28 & 20.208 & 0 & 0 & 90 & 144.570 \\
\hline Reserva de Desenvolvimento Sustentável & 2 & 1.026 & 29 & 110.090 & 5 & 176 & 36 & 111.293 \\
\hline Reserva de Fauna & 0 & 0 & 0 & 0 & 0 & 0 & 0 & 0 \\
\hline Área de Proteção Ambiental & 32 & 100.101 & 185 & 334.898 & 77 & 25.922 & 294 & 460.922 \\
\hline Área de Relevante Interesse Ecológico & 16 & 447 & 24 & 443 & 8 & 32 & 48 & 921 \\
\hline RPPN & 634 & 4.832 & 147 & 686 & 1 & 0 & 782 & 5.517 \\
\hline Total Uso Sustentável & 811 & 394.681 & 452 & 602.377 & 91 & 26.131 & 1354 & 1.023 .189 \\
\hline Total Geral & 954 & 763.845 & 781 & 760.848 & 205 & 26.503 & 1940 & 1.551 .196 \\
\hline Área Considerando Sobreposiçăo Mapeada & 954 & 758.733 & 781 & 755.661 & 205 & 26.479 & 1940 & 1.513 .828 \\
\hline
\end{tabular}

Figura 2: Quadro consolidado das Unidades de Conservação brasileiras. Não foram consideradas no inventário as Reservas Particulares do Patrimônio Natural (RPPN). Fonte: MMA (2016).

Figure 2: Consolidate table of Brazilian's nature protected area. Were not considered in the inventory the Private Reserves of Natural Heritage (as known as RPPN). Source: MMA (2016).

O acesso ao parque pode ser acessado pela "portaria Jardim Canadá", em Nova Lima (MG), pela rodovia federal BR-040; e pela "portaria Barreiro", em Belo Horizonte (MG) (Figura 3). Além das duas portarias sua infraestrutura conta com: centro administrativo; dois centros de informações, educação ambiental e lazer; dois auditórios; casa destinada a instalação de um grupamento de Polícia Militar do Meio 
Ambiente e residências para funcionários (PEIXOTO, 2004, p.56). O parque possui ainda posto do Corpo de Bombeiros, estacionamento, sanitários, heliponto e alojamento para pesquisadores.

Em relação aos atrativos turísticos o PESRM conta com, dentre outros: mirantes (das Três Pedras, do Planeta, do Jatobá e Morro dos Veados) e trilhas (Campo Ferruginoso, Travessia, Morro III e outras), além da prestigiada beleza cênica local proporcionada pelo ondulado das serras. Quanto ao uso público, são permitidas atividades como: caminhada, educação ambiental, ciclismo e esportes (MINAS GERAIS, 2007).

Embora exista uma infraestrutura de apoio e atendimento aos visitantes instalada no parque bem como segundo parque estadual de MG com maior número de funcionários (REZENDE et al., 2010, p. 96), observa-se que na prática a mesma não é efetiva, visto que nem sempre se encontra à disposição do visitante, estando muitas vezes fechada em datas e horários em que o fluxo de visitantes é alto. A exemplo da portaria Jardim Canadá que dá acesso ao distrito de Casa Branca, Brumadinho (MG), em que o parque acaba se tornando um "estrada-parque" (SORIANO, 2006), quase sem controle de acesso.

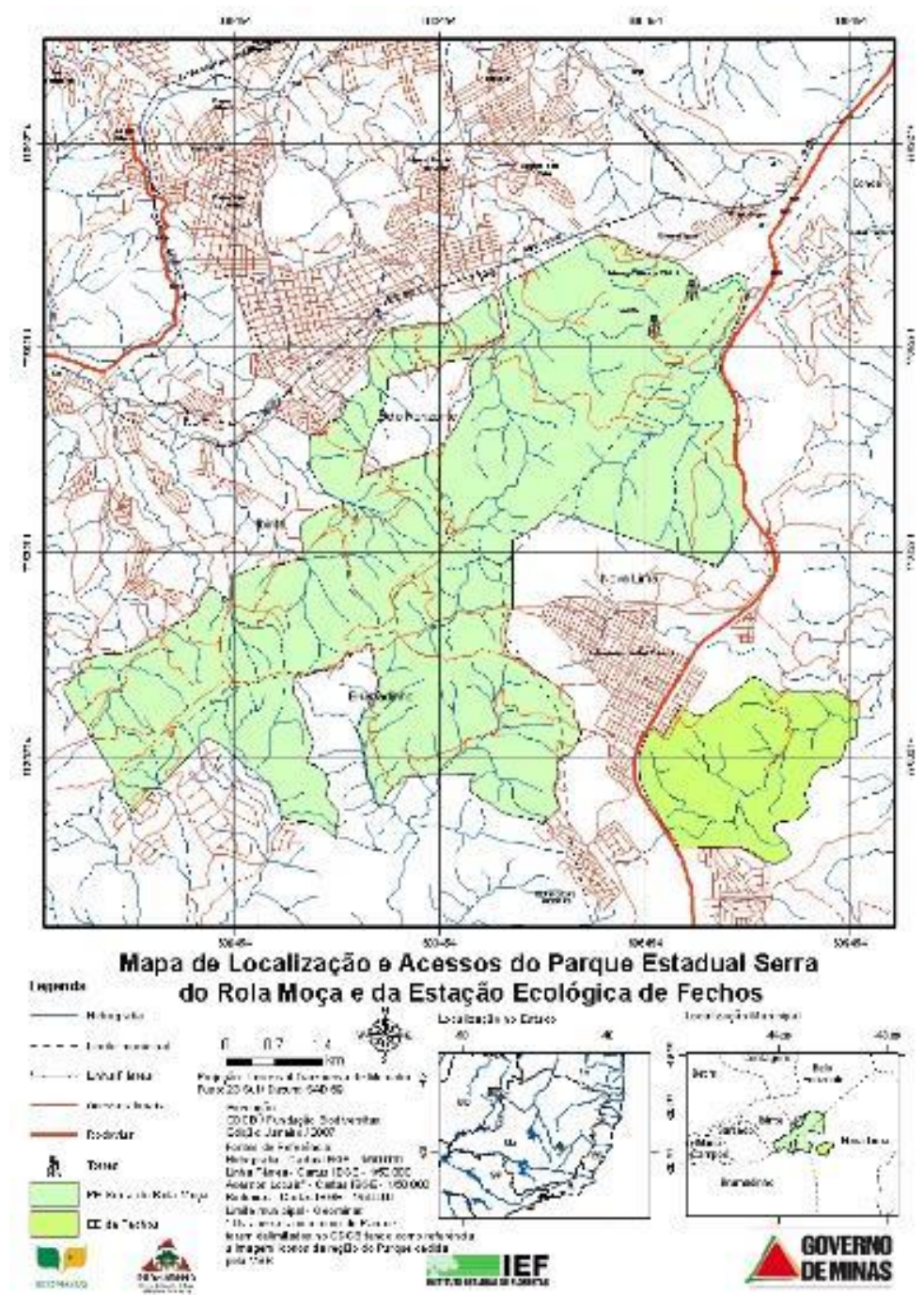

Figura 3: Mapa de Localização e Acessos do Parque Estadual da Serra do Rola-Moça.

Fonte: Biodiversitas (2007).

Figure 3: Location and access map of Serra do Rola-Moça Range State Park.

Source: Biodiversitas (2007). 
Quanto à caracterização abiótica do Parque

[...] também chamado de ambiente físico se refere às variáveis não biológicas ou abióticas, como o clima, a temperatura, o relevo, os solos, os recursos hídricos, dentre outros. Estes fatores interagem entre si e formam condições que favorecem ou limitam a ocorrência de organismos e processos naturais de uma determinada região geográfica. Os fatores abióticos são características do ambiente e influenciam de forma direta e/ou indireta a sobrevivência, o crescimento e a reprodução de todas as formas de vida de uma região e, consequentemente, a distribuição geográfica e a abundância destes organismos (BIODIVERSITAS, 2007, p.22).

Inserido na região do QFe, caracterizada pela diversidade de reservas minerais nele existentes, o PESRM também possui uma caracterização física diferenciada, caracterizada principalmente pela presença da carapaça laterítica ferruginosa, regionalmente conhecida como "cangas" (VINCENT; MEGURO, 2008).

O Parque Estadual da Serra do Rola-Moça, [...] está localizado exatamente na junção das estruturas da Serra da Moeda, que compõe a porção oeste do Quadrilátero Ferrífero, fundindo-se a norte com a Serra do Curral. Os contatos leste e oeste dessa megaestrutura são definidos por falhamentos. Apresenta um relevo dividido em compartimentos caracterizados por quatro tipos de litologias (litótipos) predominantes entre as rochas do Quadrilátero Ferrífero que afloram na área de estudo (Itabiritos, Dolomitos, Filitos e Quartzitos). Esses litótipos apresentam comportamentos físicoquímicos diferenciados frente aos processos de intemperismo e erosão (BIODIVERSITAS, 2007, p.22).

A presença das cangas caracteriza a paisagem e o relevo local e essa especificidade faz com que o PESRM seja um geossítio, dentre os que compõem a proposta do geoparque do Quadrilátero Ferrífero, de interesse internacional do ponto de vista científico, educativo, estético, cultural, histórico e turístico (AZEVEDO et al., 2012).

Outro destaque desta região é o potencial hídrico nela existente, sendo que a área do parque abriga importantes mananciais de água que abastecem parte da população de Belo Horizonte, Ibirité e Brumadinho. Hidrografia está estreitamente relacionada ao clima, que "se classifica na faixa de transição térmica entre tropical e subtropical, com intensidade de radiação solar elevada [e] regime de precipitação na região descreve um ciclo anual com verão chuvoso e inverno seco" (PEIXOTO, 2004, p.54).

Em relação ao meio biótico, este é caracterizado em função as particularidades do ambiente físico (BIODIVERSITAS, 2007, p.33). Os biomas que caracterizam o PESRM são a Mata Atlântica e o Cerrado, sendo estes considerados regiões de megadiversidade (hotspots) que constantemente sofrem ameaças e que, portanto, necessitam de maiores ações conservacionistas. A vegetação local é 
composta por quatro tipologias: a mata estacional, o cerrado, o campo altimontano e o campo rupestre (PEIXOTO, 2004, p.51).

Por estar inserido na Reserva da Biosfera Serra do Espinhaço (RBSE) ${ }^{10}$, criada em 2005, e também na Área de Proteção Ambiental Estadual Sul (APA SUL), UC de uso sustentável, o parque conta com maior apoio no que tange a conservação dos biomas nele encontrados.

Com relação à fauna do parque, esta se encontra comprometida. De acordo com o Plano de Manejo (2007) "a pressão das atividades antrópicas sobre os ambientes naturais da região onde estão inseridos o PESRM e a EEF levou a uma fragmentação dos seus habitats nativos, comprometendo a sobrevivência de diversas espécies da fauna". Entretanto, a existência de abrigos naturais em rochas de difícil acesso contribui para a manutenção da vida animal no Parque (PEIXOTO, 2004, p.54). Espécies ameaçadas de extinção como a onça parda, a jaguatirica, lobo-guará, o gato-do-mato, o macuco e o veado campeiro são algumas das encontradas no PESRM (IEF, 2016).

Ainda quanto à relação da pressão antrópica com o meio biótico:

situações como a coexistência junto às atividades mineradoras na região; o tráfego de automóveis dentro da área do parque para acesso à cidade de Ibirité, à Casa Branca (Brumadinho), ao bairro Barreiro (Belo Horizonte); as trilhas feitas por jipes e motocicletas em meio às montanhas do cerrado, ocasionando erosões no solo; a alta incidência de queimadas; a invasão das áreas de mananciais para acampamentos recreativos proibidos; a proximidade com o bairro Jardim Canadá (Nova Lima), com os bairros Independência e Mineirão (Belo Horizonte) que têm sua expansão direcionada para os limites do parque; a utilização de áreas para atividades ilícitas (depósito de lixo, abandono de carcaças de carros roubados e desova de cadáveres) entre tantos outros demonstram a fragilidade do parque e evidenciam a existência dos conflitos sociais e a falta de articulação com os poderes locais e sistemas culturais (PEIXOTO, 2004).

Estas problemáticas comprovam o quanto é delicada a relação existente entre a gestão do Parque com os demais atores sociais envolvidos no contexto do mesmo, bem como a forma como o parque lida com a forte pressão urbana por ele sofrida.

Desta forma, o PESRM, assim como outros parques situados próximos a centros urbanos, necessita de um planejamento e gestão que busquem equilíbrio entre a urbanização e a conservação ambiental, visando promover um relacionamento estável com os stakeholders com que ele interage (visitantes, moradores, empresas do entorno e administrações municipais envolvidas), como também minimizar os impactos negativos oriundos desta proximidade, sendo este um dos maiores desafios para a gestão do parque.

Ao se analisar a caracterização ambiental (biótica, abiótica e socioeconômica) do PESRM, observa-se que devido ao contexto caracteristicamente urbano onde está inserido, o planejamento e desenvolvimento local é uma atividade complexa que deve ser criteriosamente pensada em seus diferentes âmbitos, dentre eles a visitação pública local. 
(...) a visitação quando realizada de forma democrática e não excludente, é uma ferramenta de fundamental importância para a conscientização de toda a sociedade a respeito da necessidade do estabelecimento das áreas protegidas e da proteção do meio ambiente em geral, devendo ocupar uma posição de destaque como estratégia de política ambiental (MMA, 2011 apud MOREIRA 2011, p. 45).

Para Takahashi (2004) "o uso público em Áreas Protegidas tem sido progressivamente percebido como uma das mais eficientes estratégias de geração de receita para a proteção e manutenção dessas áreas". Apesar do potencial turístico que o PESRM possui, o uso público local vem ocorrendo de maneira não muito planejada, o que acarreta uma série de impactos negativos dentre eles a degradação ambiental. A visitação ao parque é gratuita e ocorre diariamente no período diurno, das 08:00 as 17:00 horas. Entretanto, um maior planejamento turístico tende a contribuir de forma a minimizar estes e outros impactos negativos, bem como auxiliar o desenvolvimento local.

Dentre as atividades realizadas pelos visitantes no parque, destacam-se as recreativas, de lazer e esportes como, por exemplo, trilhas, caminhadas e contemplação da natureza nos mirantes. Estas atividades na maioria das vezes estão ligadas a apreciação da biodiversidade, sem ênfase na geodiversidade.

Entretanto, devido à geodiversidade premente neste parque, observa-se o potencial de desenvolvimento de atividades que envolvam o patrimônio geológico local, sendo estas voltadas apreciação, conhecimento/entendimento, divulgação, interpretação e, por conseguinte a conservação patrimônio geológico nele existente.

Neste sentido, destaca-se o geoturismo, onde a interpretação é uma das palavras-chave, sendo vista como uma "forma de sensibilizar o visitante sobre a importância e a necessidade de conservar o patrimônio geológico" (RUCHKYS, 2007, p.23). Já Moreira (2008, p.70) aponta que "no geoturismo se entende que não há somente a apreciação da paisagem, e sim também sua compreensão, realizada com o auxílio dos meios interpretativos". Sendo assim, a interpretação dos aspectos geológicos em um parque, neste caso o PESRM, pode ser realizada de diferentes formas como através de trilhas interpretativas, painéis que exponham a história geológica local, folhetos, guias, dentre outros (NASCIMENTO et al., 2008).

Em que o único elemento da infraestrutura turística local voltada exclusivamente à divulgação do Patrimônio Geológico existente é um painel no Mirante dos Veados (Figura 4). Este contém resumidamente explicações acerca da geodiversidade presente no parque, destacando a presença das cangas lateríticas, um elemento geodiverso que caracteriza o PESRM. No entanto o mesmo se encontra deteriorado, com a presença de pichações.

A importância em trabalhar a atividade geoturística em áreas naturais, bem como no PESRM, se justifica pelo fato deste segmento estar voltado para valorização e conservação da "metade esquecida do meio ambiente" que é a geodiversidade. Esta merece tanta atenção quanto à biodiversidade uma vez que também sofre impactos de acordo com a forma com qual é utilizada. 


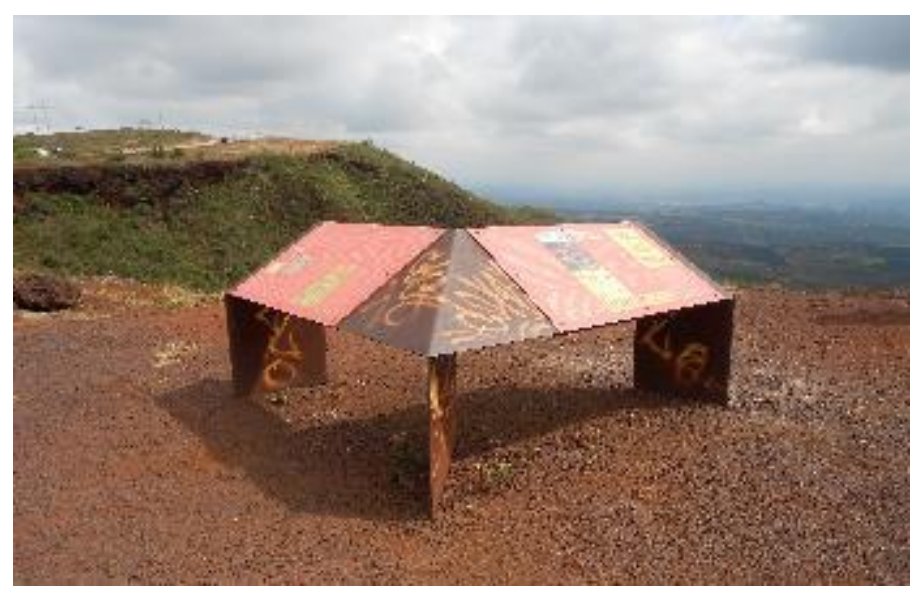

Figura 4: Foto do painel com informações geológicas situado no Mirante dos Veados, Parque Estadual Serra do Rola-Moça. Fonte: Gabriela Ribeiro (2015).

Figure 4: Panel picture with geological information located in the Deer Belvedere, State Park RolaMoça Range. Source: Gabriela Ribeiro (2015).

A atividade geoturística no PESRM, se bem planejada, tende a contribuir diretamente para o desenvolvimento do parque de diferentes formas como: proteção e reconhecimento do patrimônio geológico; educação geológica e ambiental dos visitantes, pois favorece a compreensão do ambiente; aumento da consciência da população local e turistas a respeito do patrimônio geológico; auxilio no desenvolvimento de regiões e municípios, sendo uma estratégia para desenvolver economicamente uma região; entre outros (MOREIRA, 2008, p.73), sendo este último de especial interesse devido ao contexto onde o parque está inserido, visto que é uma forma de articular os gestores do parque com os demais atores sociais envolvidos (visitantes, moradores, empresas do entorno e administrações municipais envolvidas).

Investigou-se nesta pesquisa como o geoturismo acontece no PESRM. Mesmo sem planejamento adequado, o geoturismo tem contribuído para 0 desenvolvimento do PESRM? Existem entre os visitantes do PESRM potenciais geoturistas? Como o geoturismo pode ser pensado e desenvolvido de acordo com a realidade do parque? Estes e outros questionamentos podem ser respondidos através da análise de um dos elementos de grande importância que fazem parte do cotidiano bem como da propagação do PESRM que são os visitantes.

\section{Perfis dos visitantes do Parque: de ecoturistas a geoturistas?}

Ao se planejar o desenvolvimento um determinado segmento turístico em uma localidade, entre eles o geoturismo, um aspecto importante a ser analisado é o perfil de seus visitantes. Através desta análise é possível traçar estratégias de desenvolvimento e implementação turística, de forma a otimizar a gestão do uso público.

A Pesquisa de Demanda Turística no Estado de Minas Gerais (2014) ressalta que: 
o levantamento de dados estatísticos do turismo possibilita ao poder público criar políticas eficazes para a atividade, ao compreender o perfil dos visitantes e o impacto que causam em cada destino turístico de um determinado território. A existência de estatísticas exatas sobre o turismo é de vital importância para determinar os seus impactos diretos ou indiretos na economia, para auxiliar no planejamento e desenvolvimento de novos produtos turísticos, para determinar as características do turista, para permitir a formulação de estratégias promocionais e de marketing e para detectar mudanças nas preferências e características do turista.

Assim sendo, através da identificação do perfil do público de uma localidade, neste caso de uma área protegida (o PESRM), é possível identificar seus interesses, motivações, preferências e percepções; a forma como o mesmo se relaciona e impacta o espaço; bem como colaborar com gestão ambiental local. A caracterização dos usuários e visitantes de áreas protegidas é vista como condição necessária para o planejamento do uso público dessas áreas (HORNBACK; EAGLES, 1999; TAKAHASHI, 2004).

Estudos de caracterização dos visitantes e do tipo de uso público que estes realizam, além dos impactos que cada um desses usos provoca na área visitada; segundo Takahashi (2004), podem auxiliar na busca da conciliação entre a conservação da biodiversidade e as atividades típicas da visitação que são a recreação em contato com a natureza, a educação e a interpretação ambiental (PIRES; MUNIZ, 2010, p.352).

No caso do PESRM através da análise do perfil de seus visitantes torna-se possível identificar os potenciais geoturistas existente neste parque.

Considerando observado que a interpretação é um elemento fundamental para a prática do geoturismo os geoturistas podem ser categorizados em três níveis, estando eles em sua maioria inseridos no primeiro nível:

Nível 1: geralmente curiosos, de certa forma sem conhecimento, visitantes casuais;

Nível 2: interessado, tendo feito uma decisão relativamente consciente de visitar atrativos ligados ao patrimônio geológico;

Nível 3: tendo feito a decisão consciente de visitar (MILLER, 1991 apud RUCHKYS, 2007, p.26).

Para a análise do perfil dos visitantes do PESRM foi utilizado questionário estruturado qualitativo e quantitativo, elaborado e aplicado considerando modelos de autores com o mesmo escopo como Drumond (2002) e Babbie (2003) sob licença de pesquisa em Unidades de Conservação número 23/2013 concedida pelo Instituto Estadual de Florestas. Estes foram aplicados no período de três dias, 01/05/2015 à 03/05/2015, com uma amostra total de cinquenta visitantes entrevistados. 
O objetivo da pesquisa com esse público foi de traçar o perfil do visitante deste parque (naquele período) com o intuito de identificar se há entre os visitantes potenciais geoturistas. A abordagem dos visitantes bem como a aplicação dos questionários ocorreu em sua maioria no período da manhã no Mirante dos Veados (local de maior concentração dos visitantes), seguido do Mirante Estrada do Alojamento e da Trilha Campo Ferruginoso (Figura 5).

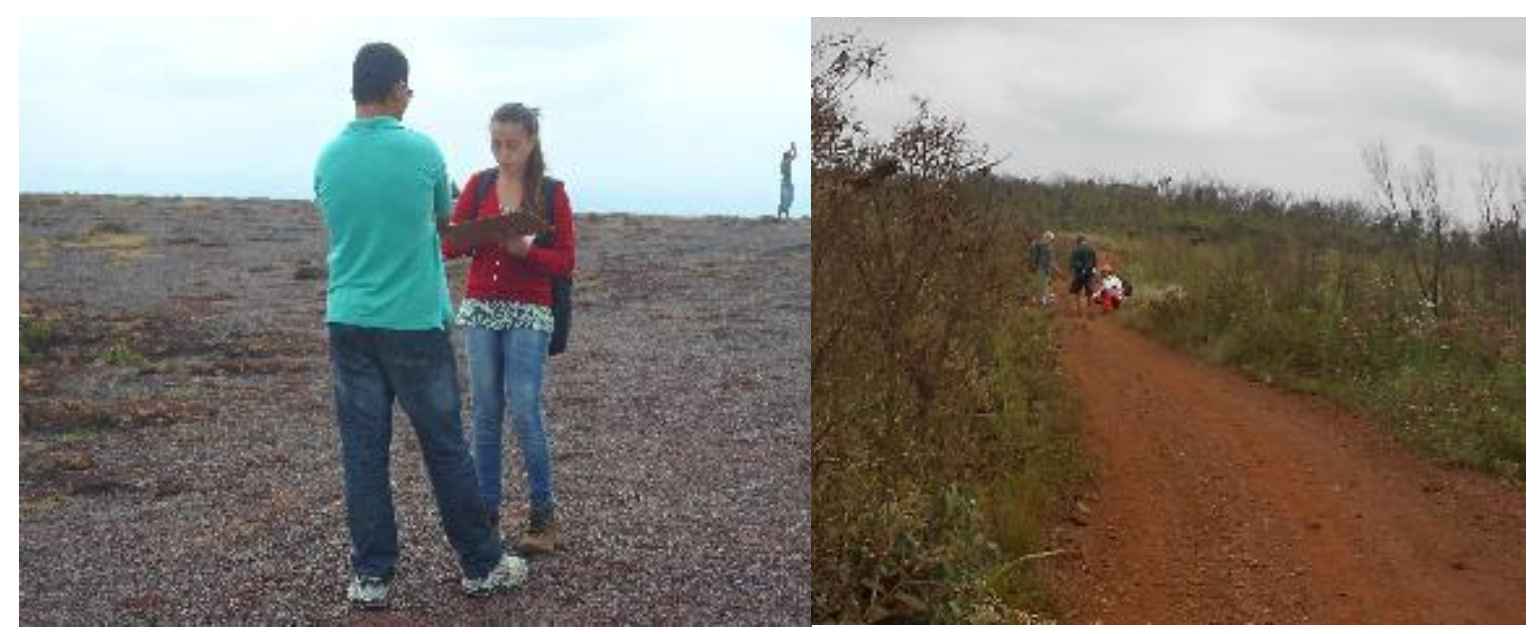

Figura 5: (esquerda) Aplicação de questionário no Mirante dos Veados (PESRM); e (direita) Aplicação de questionário na Trilha Campo Ferruginoso (PESRM).

Fonte: Ricardo Fonseca Filho (2015).

Figure 5: (left) Form interview within visitor in Deer Belvedere (Rola-Moça Range State Park); and (right) Form interview within visitor in Ferruginous Field Trail (Rola-Moça Range State Park).

Source: Ricardo Fonseca Filho (2015).

A partir da análise dos dados tabulados após a pesquisa de campo, constatouse que a maioria dos visitantes do PESRM é de Belo Horizonte (58\%), seguida de Contagem (10\%) e depois de São Paulo (8\%) (Figura 6). Desta forma nota-se que o visitante é, em sua maioria, morador e não turista ${ }^{11}$ ou excursionista ${ }^{12}$, já que a UC está em quatro municípios da Grande BH: Brumadinho, Ibirité, Nova Lima e Belo Horizonte.

Comparando-se tais dados com outros estudos como a pesquisa da demanda turística do PESRM realizada por Peixoto (2004) verifica-se uma correlação diretamente proporcional, já que $63,16 \%$ dos visitantes são de $\mathrm{BH}$. Por sua vez, a Pesquisa da Demanda Turística no Estado de Minas Gerais (MINAS GERAIS, 2014) observa que o belorizontino corresponde a $15 \%$ dos visitantes do Estado. 


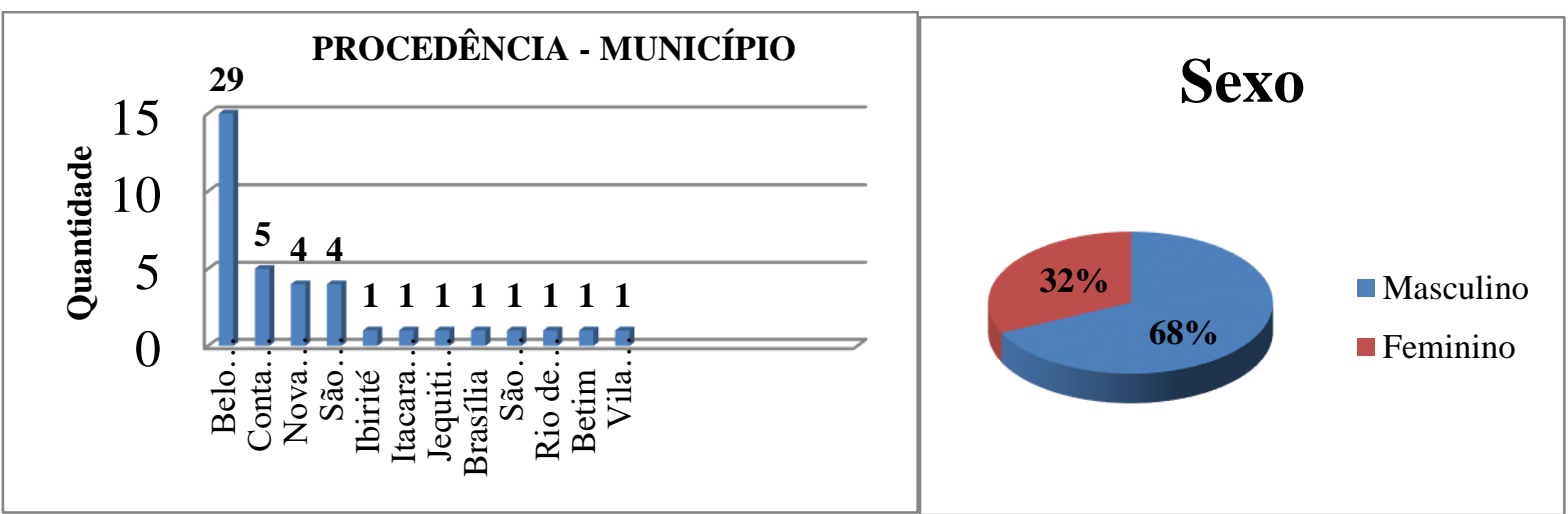

Figura 6: Gráfico de procedência (Esquerda) e de sexo (Direita) dos visitantes do Parque Estadual da Serra do Rola-Moça. Fonte: Ricardo Fonseca Filho e Gabriela Ribeiro (2015).

Figure 6: Origin and gender of Rola-Moça Range State Park visitors.

Source: Ricardo Fonseca Filho e Gabriela Ribeiro (2015).

Observa-se que a grande maioria dos visitantes do PESRM é de Minas Gerais (Figura 6, esq.) (86\%), assim como no Parque Estadual do lbitipoca onde os mineiros representam 50,3\% dos visitantes (LADEIRA et al., 2007).

O perfil do visitante é homem (68\%) (Figura 6, dir.); casado (58\%), seguido de solteiro (34\%) e divorciado (8\%); católico (42\%); tendo idade entre 26 a 45 anos (64\%) (Figura 7, esq.). Estes dados correspondem com os obtidos por Michael Bruno (2011), referentes ao perfil dos visitantes do Parque Municipal Fazenda Lagoa do Nado situado na região metropolitana de Belo Horizonte (MG), onde os visitantes do sexo masculino correspondem a $57,33 \%$, para $42,66 \%$ do sexo feminino, e faixa etária com maior representatividade variando entre 25 e 45 anos (39\%). Entretanto, quando confrontados com Peixoto (2004), se difere em partes visto que o visitante do PESRM por ele encontrado é caracterizado por serem $52,63 \%$ do sexo masculino e $47,37 \%$ do sexo feminino, demonstrando assim uma distribuição equitativa, e este possui, em sua maioria, idade entre 25 a 29 anos.

Nota-se que o público do PESRM é em sua maioria composto por jovens (Figura 7, esq.). Porém, é bastante representativa também a faixa etária entre 46 a 60 anos. Quanto ao agrupamento (Figura 7, dir.) o visitante do PESRM é acompanhado da família (36\%), seguido de amigos (26\%) e cônjuge/ namorado(a) $(20 \%)$.

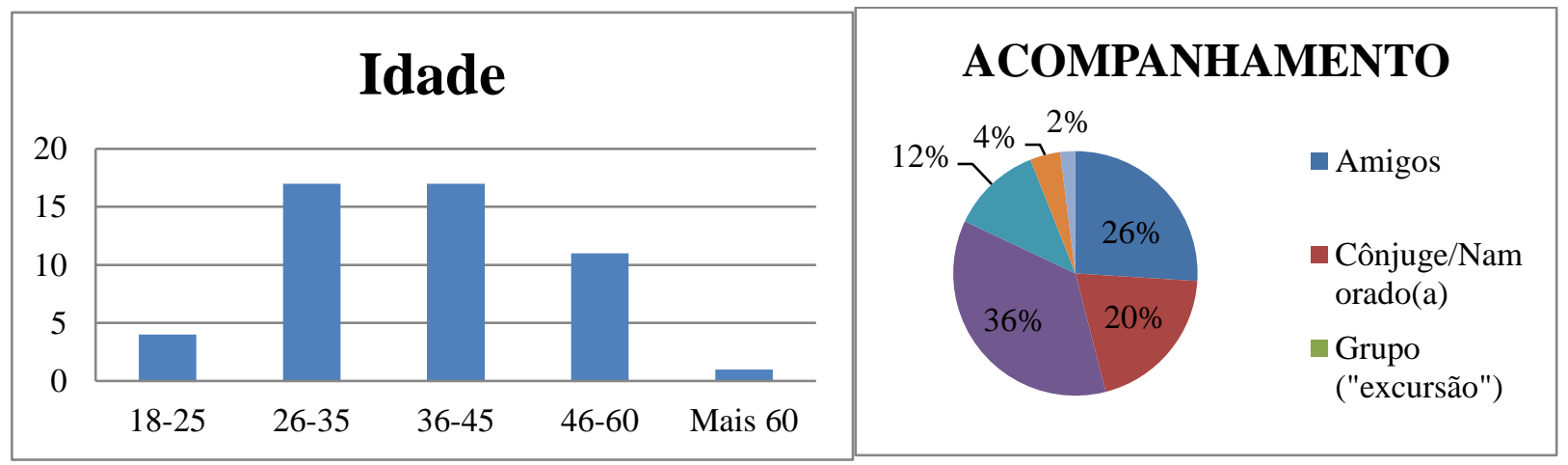

Figura 7: Gráfico idade (Esquerda) e agrupamento (Direita) dos visitantes.

Fonte: Ricardo Fonseca Filho e Gabriela Ribeiro (2015).

Figure 7: Age (Left) and grouping (Right) of Rola-Moça Range State Park visitors.

Source: Ricardo Fonseca Filho e Gabriela Ribeiro (2015). 
O visitante do PESRM trabalha remuneradamente (92\%) e seu salário gira em torno de 4 a 8 salários mínimos ${ }^{13}$ (Figura 8, esq.). Quanto à escolaridade (Figura 8, dir.), o visitante do PESRM tem, em sua maioria ensino Superior Completo (38\%), seguido do Ensino Médio Completo (32\%), Pós-Graduação e Superior Incompleto, ambos (12\%) cada, Fundamental Incompleto (4\%) e Médio Incompleto (2\%).

Estes dados, referentes à escolaridade, são diretamente proporcionais a resultados obtidos em outros estudos realizados em Minas Gerais como: a Pesquisa de Satisfação do Turista de Belo Horizonte (2015) onde foi constatado que a maioria dos visitantes de $\mathrm{BH}$ possui Ensino Superior Completo $(30,1 \%)$, seguido do Ensino Médio Completo (28,7\%); como também o estudo realizado por Ladeira et al. (2007), referente ao perfil dos visitantes do Parque Estadual do Ibitipoca-MG, onde se observa uma predominância de pessoas com nível superior, sendo que $76 \%$ estão cursando ou possuem o terceiro grau. A partir destes resultados pode-se constatar que grande parte dos visitantes de UC em MG possui ensino superior completo.

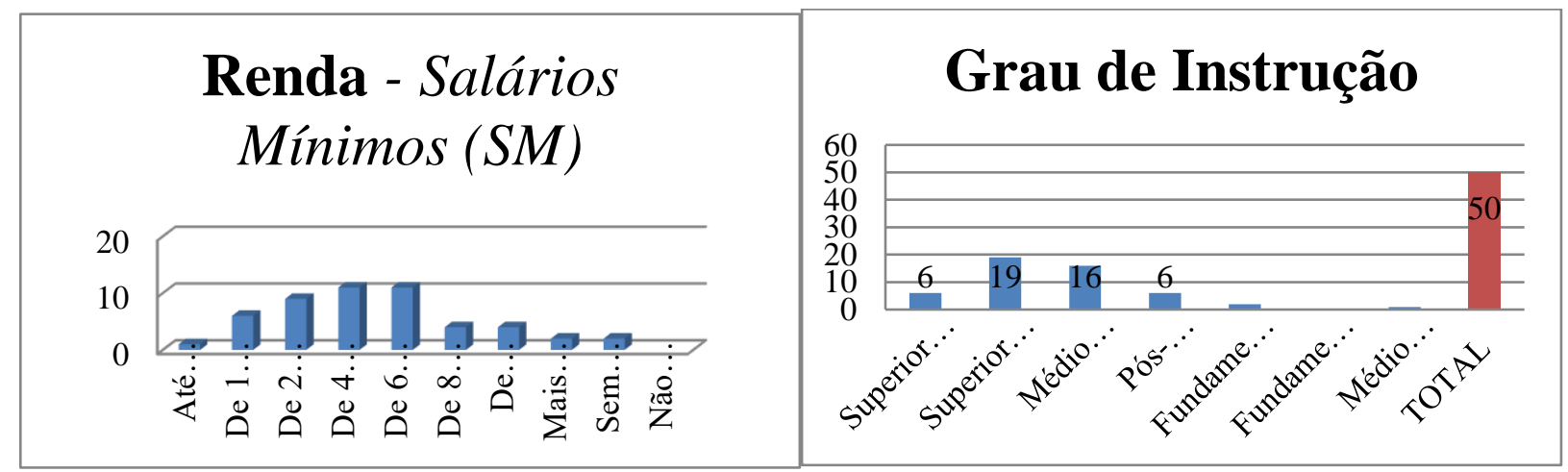

Figura 8: Gráfico de renda (Esquerda) e grau de instrução (Direita) dos visitantes do Parque Estadual da Serra do Rola-Moça. Fonte: Ricardo Fonseca Filho e Gabriela Ribeiro (2015).

Figure 8: Income (Left) and education (Right) of Rola-Moça Range State Park visitors.

Source: Ricardo Fonseca Filho e Gabriela Ribeiro (2015).

Em virtude do nível elevado de escolaridade dos visitantes do PESRM, espera-se que este fato facilite o processo de implementação de atividades ligadas à educação e interpretação ambiental, bem como a adoção das medidas informativas e educativas no sentido de preservar os atrativos e infraestrutura do parque (LADEIRA et al., 2007).

Apesar de a situação socioeconômica não determinar a eficácia do processo de acordo com os princípios de educação ambiental, porém esse fato pode contribuir, e muito, para que um programa de educação do visitante seja bem recebido e aceito pelo público, pois as pessoas que visitam o parque já possuem uma bagagem educacional que as ajuda a compreender a importância das atitudes e ações de todos nas áreas naturais (LADEIRA et al., 2007, p.1096). 


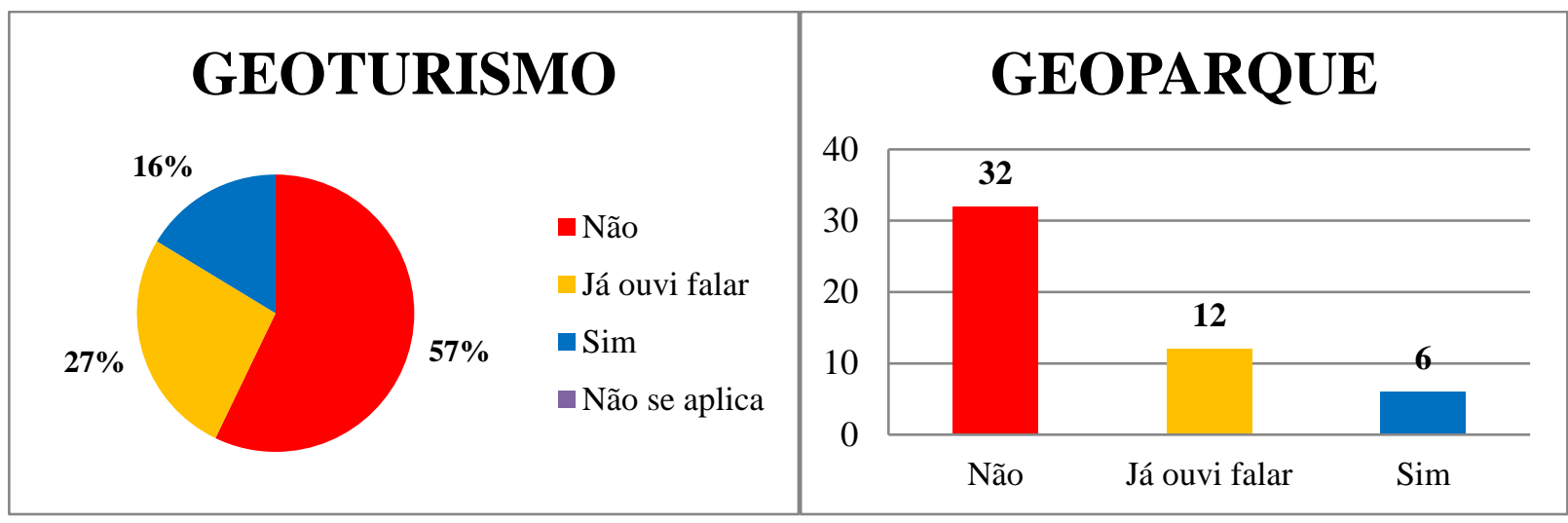

Figura 9: Gráfico de conhecimento sobre "geoturismo" (Esquerda) e sobre "geoparque" (Direita) dos visitantes do Parque Estadual da Serra do Rola-Moça.

Fonte: Ricardo Fonseca Filho e Gabriela Ribeiro (2015).

Figure 9: Geotourism (Left) and Geopark (Right) knowledge of Rola-Moça Range State Park visitors. Source: Ricardo Fonseca Filho e Gabriela Ribeiro (2015).

Ao analisar as questões referentes ao segmento turístico do geoturismo constatou-se que, o visitante do PERSM predominantemente desconhece este segmento (56\%) (Figura 9, esq.), dados similares a Oliveira e Silva (2014), em que $51 \%$ dos entrevistados no Geoparque Bodoquena-Pantanal não conheciam o significado do geoturismo. Entretanto, pode-se considerar que dentre os visitantes que responderam saber o que é geoturismo (16\%) ou afirmou já ter ouvido falar a respeito (26\%), provavelmente exista o perfil denominado geoturista, praticando tal atividade mesmo que inconscientemente ou potencias praticantes para esta atividade. Há de se considerar a margem de erro existente nas respostas visto que, pode haver dentre os visitantes que responderam "sim", alguns que não sabem com clareza o que é, tendo apenas ouvido falar a respeito do geoturismo, e reciprocamente, visitantes que responderam "já ouvi falar", mas que na verdade sabem de fato o que é geoturismo.

Em relação aos geoparques, a maioria dos entrevistados diz não saber o que é (64\%), seguido dos que já ouviram falar (24\%) e por fim os que dizem saber o que é (12\%) (Figura 9, dir.). Tal resultado demonstra o desconhecimento, por parte da maioria dos visitantes, de estarem em um geoparque. Através deste dado observase que embora o parque esteja inserido no Geoparque do Quadrilátero Ferrífero, o que o torna um atrativo ainda mais diversificado em relação a sua oferta, a divulgação de tal fato ainda se encontra restrita a veículos ligados a meios científicos como, artigos, periódicos, livros de pesquisadores do tema, sites dos órgãos responsáveis pela criação e desenvolvimento dos geoparques como a UNESCO e o CPRM (Serviço Geológico do Brasil) a exemplo, não estando, portanto ainda disponível de uma forma mais acessível e abrangente para o conhecimento do público em geral, como observado por Peixoto (2014), que aponta a falta de informação da população acerca do PESRM, que identificou a presença de pessoas na UC que afirmam desconhecer o local como um parque.

Nesta linha Bento (2014) destaca a importância da interpretação ambiental do Parque Estadual do Ibitipoca (MG), o que os painéis, assim como no PESRM, como propostos para a UC estudada pela autora, poderiam facilitar o que chama "geointerpretação", como exemplificado na Figura 4. 
Enquanto que Carvalho e Rudzewicz (2016), entrevistando gestores de cinco geoparques brasileiros, incluindo o Geoparque do QFe demonstraram que somente dois dos geoparques têm geoturismo como modalidade de turismo praticada, concluindo que "o turismo nos geoparques requer o desenvolvimento de estratégias administrativas para planejar e monitorar o fluxo de visitantes", justificando a presente pesquisa e destacando a importância do controle do uso público e em especial a visitação deste segmento turístico.

Figueiredo et al. (2015), em estudo sobre a Pedra de Ingá (PB), que tem potencial para inventário de sítio paleontológico, demonstraram que visitantes da área protegida têm interesse em conhecer mais sobre o geoturismo do patrimônio geológico-geomorfológico.

Gouveia da Silva (2015), em entrevista a amostra no município paraibano de Gurjão demonstrou resultado oposto, com três quartos parte da amostra de professores conhecedora do geoturismo e toda a amostra selecionada da comunidade não-docente como conhecimento indireto do geoturismo (a questão abordava se o município tem potencial para o geoturismo, o que implica o conhecimento do termo). Santos e Carvalho (2012) também entrevistaram comunidade de São José do Itaboraí (RJ) e a grande maioria acredita nos efeitos econômicos e sociais positivos do geoturismo e da criação de um "parque paleontológico" (que se aproxima de um mix de geoparque e de unidade de conservação, em especial do tipo Monumento Natural), embora parte das respostas sobre os efeitos ambientais sejam negativos, como a não conservação (resíduos sólidos e vandalismo). O que, indiretamente, corrobora Gouveia da Silva (idem) pelos entrevistados terem ciência indireta do geoturismo e de um geoparque.

Conclui-se que os $57 \%$ que não sabem o que é geoturismo e os $64 \%$ que não sabem que estão num Geoparque, somados aos que "ouviram falar" - que não implica um conhecimento técnico, corroborando com Onary-Alves et al. (2015), e consequente conservação do patrimônio geológico e sua geodiversidade - foram instigados para uma percepção da paisagem permitindo uma valoração da mesma, seja científico-educacional, cultural, funcional ou econômica, como apontam Figueiró et al. (2013).

Os resultados obtidos, tanto na pesquisa bibliográfica como na pesquisa de campo, permitem e auxiliam na criação estratégias relacionadas à gestão do uso público (TAKAHASHI, 2004), bem como do possível desenvolvimento do segmento do geoturismo no parque (e geoparque), de forma a colaborar com a atividade turística local. A partir das informações obtidas por meio dos visitantes, pode-se avaliar ainda que:

- A razão do perfil dos visitantes ser caracterizado por moradores, em especial da capital mineira (Figura 6), pode ser explicada pela proximidade do parque com o município, entretanto, este fato pode ser explicado também pela falta de divulgação do parque, seja por meio da sinalização ou por outros veículos como a internet, o que faz com que o parque deixe de receber visitantes de outras localidades - fato este que implica uma maior divulgação do parque, tal qual sugerido por O'Loughlin e lemon (2008) em que "comunicações e promoções são os elementos-chave para o marketing do patrimônio geológico";

- Outro fato que pode ser explicado pela divulgação não devidamente realizada do parque é em relação ao conhecimento dos visitantes acerca da área que 
está sendo visitada, uma vez que, como visto na questão referente ao geoparque (Figura 9), grande parte dos visitantes desconhece o que é um geoparque, bem como o fato de estarem visitando um;

- O fato dos visitantes possuírem em sua maioria um nível elevado de escolaridade (Figura 8) pode ser um facilitador ou dificultador do desenvolvimento e a implementação de atividades educativas e interpretativas para o geoturismo no parque, pois aceitariam e demandariam melhor, ou mesmo exigiriam um produto mais elaborado respectivamente;

- Os visitantes em geral permanecem cerca de meio dia no parque, sendo assim as atividades educativas, interpretativas, em especial as relacionadas ao geoturismo, devem ser planejadas com uma duração que respeite o tempo de permanência dos visitantes, ora excursionistas.

Para além dos dados anteriormente citados, os demais fatores referentes a característica do visitante local influenciam na criação de estratégias para a gestão do uso público como: idade, renda financeira, motivação da visitação, dentre outros. Sendo assim, para que a atividade turística local ocorra de forma planejada visando gerar o mínimo de impacto possível é fundamental conhecer e considerar as características da demanda turística.

Embora tenha sido verificado por meio dos dados obtidos que a maioria dos visitantes do PESRM desconhece o geoturismo, o potencial de desenvolvimento deste segmento que o parque (e geoparque) possui é relevante, assim como a possível existência de visitantes praticando tal atividade, mesmo que ainda de forma sutil.

Alguns autores vêm realizando pesquisas referentes ao perfil do geoturista. Hose (1996) é um destes autores e suas pesquisas visam traçar o perfil dos geoturistas na Grã-Bretanha bem como os tipos de interpretação relacionados aos sítios geológicos. O perfil de geoturista traçado é:

freqüentemente são turistas acidentais descobrindo o patrimônio geológico por acaso; muito poucos têm conhecimentos de geologia; os adultos têm geralmente idades superiores há trinta anos; viajam geralmente em casais ou em pequenos grupos familiares com crianças; gostam de centros interpretativos e estão dispostos a pagar apenas entradas moderadas; só observam os painéis interpretativos ao ar livre durante um curto período de tempo (HOSE, 1996 apud RUCHKYS, 2007 p.26).

Diferentemente de Miller (1991) no que tange a um aspecto comum no perfil dos geoturistas: o fato destes estarem em sua maioria praticando geoturismo, de certa forma, inconscientemente uma vez que são visitantes casuais descobrindo o patrimônio geológico eventualmente. E ainda Moreira (2008), que considera geoturistas "pessoas que têm o interesse em conhecer mais os aspectos geológicos e geomorfológicos de um determinado local, sendo esta a sua principal motivação na viagem", desconsiderando assim a possibilidade de descobrir estes aspectos ao acaso.

Considerando os estudos realizados por Hose (1996) e Miller (1991), acreditase que os prováveis geoturistas existentes no PESRM são também caracterizados 
por visitantes eventuais que muitas vezes "não tem conhecimentos aprofundados acerca da geologia, mas que se interessam pelo patrimônio geológico e o descobre mesmo que por acaso", estando assim inseridos na categoria "Nível l", determinada por Miller (1991).

Contudo, embora os visitantes que afirmaram conhecer ou já ter ouvido falar acerca do geoturismo (43\%) representem um número inferior aos que responderam não conhecer tal segmento (57\%), este dado traz uma perspectiva positiva e esperançosa em relação ao desenvolvimento do mesmo uma vez que demonstra que apesar de ser um segmento turístico considerado recente quando comparado a outros como a exemplo ecoturismo, aos poucos ele vem se tornando conhecido, conquistando assim seu espaço.

\section{Considerações finais}

O Parque Estadual da Serra do Rola-Moça, devido ao contexto onde esta inserido (região do Quadrilátero Ferrífero, Serra do Espinhaço, área de proposta de um geoparque etc.), sua caracterização (meio físico e meio biótico) bem como a representatividade que possui (área protegida situada em contexto urbano), possui um elevado potencial de desenvolvimento turístico, em especial para o recente segmento turístico que vem sendo desenvolvido visando promover os aspectos geológicos de uma localidade que é o geoturismo.

Por meio de levantamento bibliográfico e de dados acerca dos visitantes do PESRM coletados em campo, foi possível analisar a forma como a atividade turística, mais especificamente o geoturismo, vem acontecendo neste parque.

Ao analisar os dados obtidos foi constatado que a maioria dos visitantes do PESRM ainda desconhece o geoturismo, estando assim inseridos em outros segmentos turísticos como, por exemplo: o ecoturismo, onde há uma usual valorização da biodiversidade apenas. No entanto é provável que dentre os visitantes entrevistados haja a presença de alguns geoturistas, praticando tal atividade ainda que inconscientemente como também de potenciais visitantes para esta prática, considerando ser reconhecido como geoturista o visitante que não apenas aprecia feições e aspectos geológicos como também adquire conhecimentos acerca do mesmo.

Embora os resultados obtidos a partir dos visitantes do PESRM demonstrem que o geoturismo ainda não é um segmento consolidado neste parque, é considerável o potencial que o mesmo possui para o desenvolvimento de tal segmento.

O geoturismo configura-se em uma proposta baseada na formação de uma consciência mais abrangente acerca da conservação ambiental, que visa para além da biodiversidade a conservação da geodiversidade, suporte para a vida na terra que também carece de atenção e cuidado. Desenvolver este segmento no PESRM, assim como em outras unidades de conservação, para além da diversificação da oferta (por ser um diferencial dentre as práticas turísticas que usualmente ocorrem nas unidades de conservação) é uma forma de conscientizar ainda mais os visitantes sobre a importância da conservação do ambiente como um todo (recursos bióticos e abióticos), além de contribuir com desenvolvimento econômico local e a promoção de um maior e melhor relacionamento do parque com os atores sociais a ele envolvidos. 
Contudo, conclui-se que conhecer o perfil do visitante do PESRM foi fundamental para identificar a forma como a atividade turística ocorre no parque, bem como suas possibilidades de desenvolvimento.

Espera-se que os resultados obtidos por esta pesquisa configurem-se em uma nova proposta para a gestão do uso público no PESRM, assim como em outras áreas naturais, que visem a conservação do ambiente como um todo (bio- e geodiversidade), o favorecimento da atividade turística por meio do geoturismo, e a contribuição para um maior conhecimento, sensibilização e valorização do meio abiótico por parte dos visitantes desta unidade de conservação.

\section{Referências Bibliográficas}

AZEVEDO, Ú.R.; MACHADO, M.M.M.; CASTRO, P.T.A.; RENGER, F.E.; TREVISOL, A.; BEATO, D.A.C. Geoparque do Quadrilátero Ferrífero - proposta. In: SCHOBBENHAUS, C.; SILVA, C.R. (org.). Geoparques do Brasil - propostas. Serviço Geológico do Brasil. Volume 1, 2012.2 Disponível em:<http://www.cprm.gov.br/publique/media/quadrilatero.pdf>. Acesso em: 17 Maio 2016.

BIODIVERSITAS. Plano de Manejo do Parque Estadual da Serra do Rola-Moça. Belo Horizonte, 2007.

BRASIL. Diretrizes para uma Política Nacional de Ecoturismo. Brasília: Ministério da Indústria, do Comércio e do Turismo e Ministério do Meio Ambiente, dos Recursos Hídricos e da Amazônia Legal, 1994.

BRASIL. Diretrizes para visitação em Unidades de Conservação. Brasília: Ministério do Meio Ambiente, 2006.

BRASIL. Lei $\mathbf{n}^{\circ}$ 9.985, de 18 de Julho de 2000. Brasília, 2000.

CARVALHO, R.G.A.; RUDZEWICZ, L. Uma análise do desenvolvimento do geoturismo em cinco geoparques brasileiros. TURyDes, v. 8, n. 19, 2015, 14p.

GEOPARK ARARIPE. Geopark Araripe. Disponível em:<http://geoparkararipe.org.br/>. Acessado em: 17 Maio 2016.

GLOBAL GEOPARKS NETWORK. Global Geoparks Network. Disponível em:<http://geoparkararipe.org.br>. Acesso em: 17 Maio 2016.

GOUVEIA DA SILVA, E. Potencial para o geoturismo no município de Gurjão/PB a partir da avaliação de seus geossítios e da percepção da comunidade. 2015. 118 p. Natal (RN), Dissertação de Mestrado, Programa de Pós-Graduação em Turismo da UFRN.

ICMBIO. Unidades de Conservação. Disponível em:<http://www.icmbio.gov.br/portal/biodiversidade/unidades-de-

conservacao/grupos.html>. Acesso em: 17 Maio 2016.

INSTITUTO ESTADUAL DE FLORESTAS. Parque Estadual da Serra do RolaMoça.

Disponível em:<http://www.ief.mg.gov.br/component/content/198?task=view>. Acesso em: 17 Maio 2016.

LADEIRA, A.S.; RIBEIRO, G.A.; DIAS, H.C.T.; SCHAEFER, C.E.G.R.; FERNANDES-FILHO, E.; OLIVEIRA-FILHO, A.T. O perfil dos visitantes do Parque 
Estadual do Ibitipoca (PElb), Lima Duarte, MG. Sociedade de Investigações Florestais. Viçosa-MG, v.31, n.6, p.1091-1098, $2007 . \quad$ Disponível em:<http://www.scielo.br/pdf/rarv/v31n6/a14v31n6.pdf>. Acesso em: 17 Maio 2016.

LINDBERG, K.; HAWKINS, D. E. Ecoturismo: um guia para planejamento e gestão. São Paulo: SENAC São Paulo, 1995.

LOPES, L.S.O.; ARAÚJO, J.L.L. Princípios e Estratégias de Geoconservação. Observatorium: Revista Eletrônica de Geografia, v.3, n.7, p.66-78; out.2011. Disponível em:<http://www.observatorium.ig.ufu.br/pdfs/3edicao/n7/5.pdf $>$. Acesso em: 17 Maio 2016.

MANTESSO-NETO, V. Geodiversidade, Geoconservação, Geoturismo, Patrimônio Geológico, Geoparque: novos conceitos nas geociências do século XXI. Conselho Estadual de Monumentos Geológicos, São Paulo, 2008.

MINAS GERAIS. Pesquisa de Demanda Turística no Estado de Minas Gerais. 2014. Disponível em:<https://www.dropbox.com/s/huivgt6gowt3d2v/0\%20$\% 20$ Apresenta\%C3\%A7\%C3\%A30 Consolidado.pdf?dl=0 >. Acesso em: 17 Maio 2016.

MOREIRA, J.C. Geoturismo: uma abordagem histórico conceitual. Turismo e paisagens Cársticas, Campinas, p. 5-10, 2010. Disponível em: $<$ http://www.academia.edu/450787/GEOTURISMO UMA ABORDAGEM HIST\%C 3\%93RICO-CONCEITUAL1>. Acesso em: 17 Maio 2016.

MOREIRA, M.O. Planejamento Turístico em Unidades de Conservação: estudo de caso do Plano de Manejo do Parque Estadual da Serra do Rola-Moça, MG. 2011. 86 p. Monografia - Departamento de Turismo, Universidade Federal de Ouro Preto, Ouro Preto.

NASCIMENTO, M.A.L. do. Geodiversidade, Geoconservação e Geoturismo trinômio importante para a proteção do patrimônio geológico. Anais... V Encontro Nacional do Ministério Público na defesa do Patrimônio Cultural; 2012, Rio de Janeiro, RJ. Disponível em: $<$ http://www.abrampa.org.br/eventos anteriores/encontro nacional/pos evento/geo diversidade geoconservacao geoturismo.pdf>. Acesso em: 14 dez. 2015.

NASCIMENTO, M.A.L.; RUCHKYS, U.A.; MANTESSO NETO, V. Geodiversidade, Geoconservação e Geoturismo - trinômio importante para a proteção do patrimônio geológico. São Paulo: Sociedade Brasileira de Geologia, 2008.

O'LOUGHLIN, T.; IEMON, K. Observe everything and communicate well: some top tips for marketing geological heritage. 2008. Disponível em:<http://www.globalgeopark.org/Articles/6353.htm>. Acesso em: 17 Maio 2016.

OLIVEIRA, M.D.; SILVA, L.F. Estratégias para o fortalecimento do geoturismo no atrativo turístico Gruta do Lago Azul, Bonito (MS). Tur. Visão e Ação, v. 16, n. 3, p. 629-655, 2014.

ONARY-ALVES, S.Y.; BECKER-KERBER, B.; VALENTIN, P.R.; PACHECO M.L.A.F. O conceito de geoparque no Brasil: reflexões, perspectivas e propostas de divulgação. Terræ Didatica, v.11, n.2, p. 94-107, 2015. Disponível em: $<$ https://www.ige.unicamp.br/terraedidatica/v11 2/PDF11-2/TD11 2-141-

4\%20.pdf>. Acesso em 17 Maio 2016. 
PEIXOTO, A.C. Diversidade na adversidade: gestão de unidade de conservação em área urbana - O Parque Estadual da Serra do Rola-Moça (MG). 2004. 158 p. Dissertação - Curso de Pós-Graduação em Ciências Sociais da Pontifícia Universidade Católica de Minas Gerais, Belo Horizonte. Disponível em:<http://www.biblioteca.pucminas.br/teses/CiencSociais PeixotoA 1.pdf $>$.

Acesso em: 17 Maio 2016.

REZENDE, J.L.P.; ALVES, R.G.; BORGES, L.A.C.; FONTES, M.A.L.; ALVES, L.W.R. Avaliação da gestão das UC do Sistema Estadual de Áreas Protegidas de Minas Gerais. GEOGRAFIAS, v. 6, n. 1, p. 87-106, 2010.

RUCHKYS, Ú.A. Patrimônio Geológico e Geoconservação no Quadrilátero Ferrífero, Minas Gerais: Potencial para a Criação de um Geoparque da UNESCO. 2007. 211 p. Tese de Doutorado, Instituto de Geociências da UFMG. Disponível em: $<$ http://www.degeo.ufop.br/terraCiencias/coloquios/llcoloquio/doc base/Patrimonio Geologico e Geoconservacao no Quadrilatero Ferrifero, Minas Gerais: Potenci al para criacao de um Geoparque da Unesco.pdf>. Acesso em: 17 Maio 2016.

SANTOS, W.F.S.; CARVALHO, I.S. Percepção dos efeitos socioeconômicos do geoturismo: o caso de São José do Itaboraí (Itaboraí, Estado do Rio de Janeiro).

Anuário do Inst. de Geoc. - UFRJ, v. 35, n. 1, p. 242-251, 2012.

SCHOBBENHAUS, C.; SILVA, C.R. Geoparques do Brasil: propostas. Rio de janeiro, 2012.

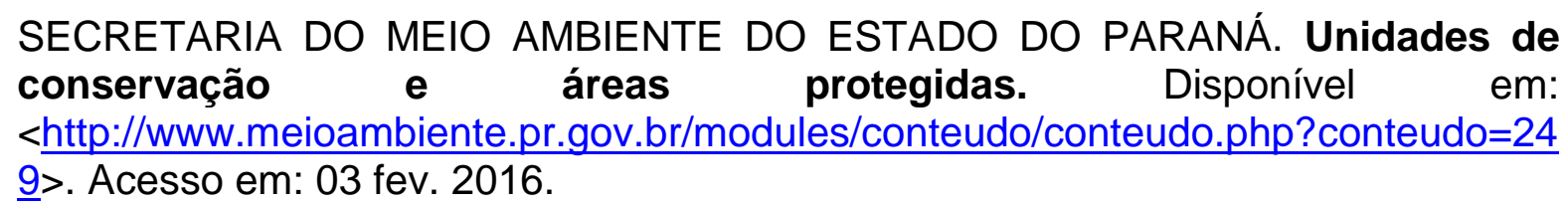

SERVIÇO GEOLÓGICO DO BRASIL. Geoparques. Disponível em:<http://www.cprm.gov.br/publique/cgi/cgilua.exe/sys/start.htm?infoid=1404\&sid= 134>. Acesso em: 17 Maio 2016.

SORIANO, A.J.S. Estrada-Parque: proposta para uma definição. UNESP - Instituto de Geociências e Ciências Exatas - Campus Rio Claro, São Paulo, 2006.

TAKAHASHI, L.Y. Uso público em unidades de conservação. Curitiba: Fundação O Boticário de Proteção da Natureza, 2004.

UNESCO. Patrimônio cultural no Brasil Disponível em:<http://www.unesco.org/new/pt/brasilia/culture/world-heritage/cultural-

heritage/>. Acesso em: 17 Maio 2016.

VINCENT, R.C.; MEGURO, M. Influence of soil properties on the abundance of plant species in ferruginous rocky soils vegetation, southeastearn Brazil. Revista Brasileira de Botânica, v. 31, n. 3, p. 377-388, 2008.

ZANIRATO, S.H.; RIBEIRO, W.C. Patrimônio Cultural: a percepção da natureza como um bem não renovável. Revista Brasileira de História. São Paulo, SP, v.26, n.51, $2006 . \quad$ Disponível em:<http://www.scielo.br/scielo.php?script=sci arttext\&pid=S010201882006000100012 >. Acesso em: 17 Maio 2016. 


\section{Agradecimentos:}

Os autores agradecem ao Departamento de Turismo pelo ensino e ao Programa de Pós-Graduação em Evolução Crustal e Recursos Naturais do Departamento de Geologia, ambos da Universidade Federal de Ouro Preto e à PróReitoria de Pesquisa e Pós-Graduação, pela pesquisa; ao Prof. Dr. Paulo de Tarso Amorim Castro e à Profa . Dra. Angélica Fortes Drummond Chicarino Varajão pela orientação e co-orientação de doutoramento respectivamente do primeiro autor; ao Instituto Estadual de Florestas pela licença de pesquisa científica; ao Parque Estadual Serra do Rola-Moça pelo apoio nos trabalhos de campo; e todos demais que contribuíram para esta pesquisa.

\section{Notas}

${ }^{1}$ O presente trabalho é parte do projeto de doutoramento do autor no Programa de PósGraduação em Evolução Crustal e Recursos Naturais, do Departamento de Geologia/Escola de Minas/Universidade Federal de Ouro Preto; e cadastrada no Instituto Estadual de Florestas sob a licença "UC 023/13"; e parte da monografia de graduação, defendida pela co-autora (2016), no curso de bacharelado em Turismo da Universidade Federal de Ouro Preto; conjuntamente com iniciação científica PIP 2S (2015) "Perfil do Geoturista em Unidades de Conservação", cadastrada na Pró-Reitoria de Pesquisa e Pós-Graduação da Universidade Federal de Ouro Preto, orientada pelo Autor.

${ }^{2}$ O SNUC foi instituído pela lei $n^{\circ} 9.985$ de 18 de Julho de 2000, sendo ele responsável por estabelecer critérios e normas para a criação, implantação e gestão das unidades de conservação (BRASIL, 2000).

${ }^{3}$ Biodiversidade, também chamada de diversidade biológica é a variabilidade de organismos vivos de todas as origens compreendendo, dentre outros, os ecossistemas terrestres, marinhos e outros ecossistemas aquáticos e os complexos ecológicos de que fazem parte; compreende ainda a diversidade dentro de espécies, entre espécies e de ecossistemas (SECRETARIA DO MEIO AMBIENTE PR, 20016).

${ }^{4}$ Geodiversidade é a variedade de ambientes, fenômenos e processos ativos, de caráter geológico, geradores de paisagens, rochas, minerais, fósseis, solos e outros depósitos superficiais que constituem a base para a vida na Terra (NASCIMENTO, 2012).

${ }^{5}$ Sítio Geológico é a ocorrência de um ou mais elementos da geodiversidade, que afloram como resultado da ação de processos naturais ou devido à intervenção humana (BILHA, 2005).

${ }^{6}$ Patrimônio geológico é a "parcela especial da Geodiversidade, materializada nos geossítios (afloramentos com características especiais), que merece proteção para as futuras gerações" (MANTESSO NETO, 2008).

7 A geoconservação visa à preservação da diversidade natural (ou geodiversidade) de significativos aspectos e processos geológicos (substrato), geomorfológicos (formas de paisagem) e de solo, pela manutenção da evolução natural desses aspectos e processos (SHARPLES, 2002 apud MANTESSO NETO, 2008).

8 Geoparque é um território definido, no qual se identificam "geossítios", que são sítios geológicos de particular importância, raridade ou beleza, que funcionam como núcleos de atração para atividades turísticas e afins, sendo o conjunto todo regido por um projeto de desenvolvimento econômico e social sustentável (MANTESSO NETO, 2008).

${ }^{9} \mathrm{O}$ Quadrilátero Ferrífero ocupa uma área de aproximadamente $7.000 \mathrm{~km}^{2}$ estando situado na porção centro-sudeste do Estado de Minas Gerais, sendo ele internacionalmente reconhecido como um importante terreno pré-cambriano com significativos recursos minerais, em especial ouro e ferro (GEOPARQUE DO QUADRILÁTERO FERRÍFERO: PROPOSTA, 2012). 
10 É considerada uma área representativa em um ecossistema onde se promovem ações para conciliar a conservação da biodiversidade e o desenvolvimento sustentável (BIODIVERSITAS, 2007).

${ }^{11}$ O turista é considerado o visitante temporário, nacional ou estrangeiro, cuja residência permanente é outra que não o local da pesquisa, e que permanece neste local pelo menos 24 horas, ou que efetua pelo menos um pernoite, permanecendo no local por, 365 dias e que não exerça função remunerada na localidade (MINAS GERAIS, 2014).

12 O excursionista é considerado o visitante temporário, nacional ou estrangeiro, cuja residência permanente é outra que não o local da pesquisa, e que permanece neste local por, no máximo 24 horas, sem realizar pernoite e que não exerça função remunerada na localidade (MINAS GERAIS, 2014).

${ }^{13}$ Salário Mínimo no momento da aplicação dos questionários (maio de 2015) de $\mathrm{R} \$ 788,00$, equivalente a cerca de US\$262.00, com dólar a $\mathrm{R} \$ 3,00$.

Ricardo Eustáquio Fonseca Filho: Universidade Federal de Ouro Preto, Ouro Preto, MG, Brasil.

E-mail: ricardoefonseca@gmail.com

Link para o currículo Lattes: http://lattes.cnpq.br/1600424426811223

Gabriela Sousa Ribeiro: Circuito Turístico Montanhas e Fé, MG, Brasil.

E-mail: gabriela_s.ribeiro@live.com

Link para o currículo Lattes: http://lattes.cnpq.br/2332024458230857

Data de submissão: 12 de abril de 2016

Data de recebimento de correções: 15 de julho de 2016

Data do aceite: 04 de agosto de 2016

Avaliado anonimamente 